\title{
ОРИЕНТИРАН КЪМ УЧЕНИКА ПОЗИТИВЕН ПОДХОД НА ВЪЗПИТАНИЕ, ОБУЧЕНИЕ И СОЦИАЛИЗАЦИЯ В ЧАСА НА КЛАСА
}

\author{
Доц. д-р Любен Витанов \\ Софийски университет „Св. Климент Охридски“
}

\begin{abstract}
Резюме. Статията разглежда ориентиран към ученика позитивен педагогически подход в часа на класа. Разглеждат се определението и неговата връзка с хуманната педагогика, позитивната психология и педагогика. Описва се конструиран модел за преподаване и учене с четири основни компонента: динамичен и споделен за подбор и структуриране на учебно съдържание; позитивен подход за възпитание и управление на класа; обучение, ориентирано към компетентности; балансиран подход на ориентирано към ученика обучение. Посочват се и методически насоки за реализация на ориентирания към ученика позитивен педагогически подход в часа на класа

Ключови думи: час на класа; позитивен педагогически подход; подходи и методи на обучение в часа на класа
\end{abstract}

\section{1. Увод}

Планирането и провеждането на часа на класа е важен и сложен по своя характер час, в който се осъществяват три сложни образователни процеса, ръководени от класния ръководител - „обучение, възпитание и социализация“"1).

За да бъдат те успешни и ефективни, трябва да бъдат прилагани комплексни педагогически стратегии и подходи. В тази статия ще опиша един от тях.

\section{2. Определение}

Ориентираният към ученика подход на възпитание и обучение поставя него, а не учителя в центъра на процеса на преподаване и учене (Blumberg 2008; Radev 2010). Това предполага неговото „активно включване“ и упражняване на повече инициатива (O’Neill 2005) в целия процес на възпитание и обучение - планиране, организация, провеждане, оценяване и др.

Така при ориентираното към ученика преподаване и учене се променят и активизират всички взаимоотношения в процеса на обучение: между учени- 
ците и учителя, между учениците, както и между учениците и дидактическата среда (фигура 1).

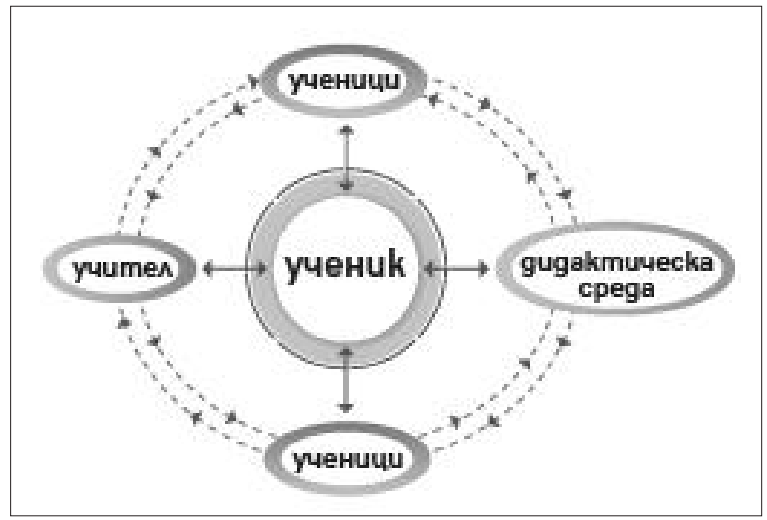

Фигура 1. Модел на ориентирана към ученика педагогическа стратегия, адаптирана и доразвита по Панина и Вавилова (2007)

Изместването на фокуса на учене от преподавателя към ученика е определяно и като конструктивистки подход, който е една от най-влиятелните образователни теории. Тя приема учениците като „конструиращи своето познание и разбиране“, така че по-самостоятелно да търсят, откриват и трансформират информация и знания (Slavin 2005, 312).

Затова и ролята на учителя при ориентирания към ученика подход е повече подкрепяща. Той участва в екипите на учениците, решава заедно с тях задачи, дава мнение, но не казва как, не дава инструкции, решения или оценки.

Така в процеса на педагогическата работа в часа на класа малките ученици може да учат, като търсят и откриват важни факти, правила и процедури. Този процес се определя от J. Bruner (1961) като „учене чрез откриване“.

Ориентираното към ученика преподаване и учене включва методи и техники от „по-висок клас“ като работа по проекти, решаване на проблеми, учене чрез откриване и др. (Johnson 2013).

\section{3. Исторически корени. Хуманна педагогика}

Позитивният педагогически подход черпи своите идеи и разбирания от личностно ориентираната хуманна педагогика, разработена от Е. Maslow, K. Rogers, C. Patterson и др. Тази концепция е позната като феноменологична и се стреми да преодолява недостатьците на традиционната образователна система, като предлага обучение, насочено повече към пълноценно развита творческа личност (Rogers 2015) и „самоактуализация“ (Maslow 2010). Така хуманистите 
смятат, че ще се повишат когнитивните и академичните резултати на учениците, ще създадат повече условия за личностно, социално и емоционално развитие.

Хуманната педагогика е свързана с два важни компонента: създаване на психологически условия за ефективно обучение и афективност в процеса на преподаване и учене. Те включват различни от когнитивните подходи стратегии на обучение, насочени към подкрепа на естествената склонност за растеж, учене и пълноценно развитие на децата.

Затова хуманното образование създава позитивна среда с различни образователни преживявания, личен опит и радост от ученето, атмосфера на взаимно уважение, разбирателство и сътрудничество като важни характеристики на „самоактуализиращите“ се личности (Rogers 2015; Maslow 2010; Patterson 1973, 1987; DeCarvalho 1991).

K. Rogers (2015) посочва няколко важни характеристики на хуманната педагогика - лична ангажираност, самоинициатива и самооценка на ученика. Към тях трябва да се добавят включването в автентични дейности и решаването на реални житейски проблеми.

\section{Фасилитаторни функции на учителя}

Една от основните функции на ориентирания към ученика подход е промяната на ролята на учителя, който прилага все повече подкрепящи естественото развитие на учениците подходи. Те се определят като „фасилитаторни“.

Фасилитатор означава улесняващ, съдействащ, подпомагащ²). В позицията си на такъв учителят променя изцяло своя подход, методи на обучение, стратегии на общуване с учениците и др.

K. Rogers (2015) определя и няколко важни изисквания към тази роля на учителя: „истинност, откритост и неподправеност в поведението“, „безусловно позитивно отношение“" и ,уважение към учениците“, както и емпатично разбиране.

Той посочва още едно важно условие, „благоприятстващо ученето на цялата личност - ученикът трябва, макар и до някаква степен да усеща, че тези нагласи съществуват у учителя“. Емпатията и искреността на учителя, стремежът да го цени и да не го съди, могат да повлияят върху съмненията и недоверчивостта, за да се повярва в новите преживявания (Rogers 2015, 250 - 252).

\section{Създаване на позитивна образователна среда}

Ориентираният към ученика подход на възпитание и обучение получава силен тласьк от съвременни научни психологически изследвания на щастието и благополучието. Те се формират основната на „позитивната психология“ и са в основата разбирането за създаване на позитивната образователна среда.

Позитивната психология и педагогика приемат важното разбиране, че в училищното образование освен ограмотяване, успех, постижения, прилежание и дисциплина трябва да се преподава и учи щастие и благополучие.

Следвайки това разбиране, M. Seligman (2017) конструира цялостна теорията за благополучието ПЕРМА, която включва пет елемента: положителна 
емоция, ангажираност, смисъл, постижение и положителни взаимоотношения (фигура 2).

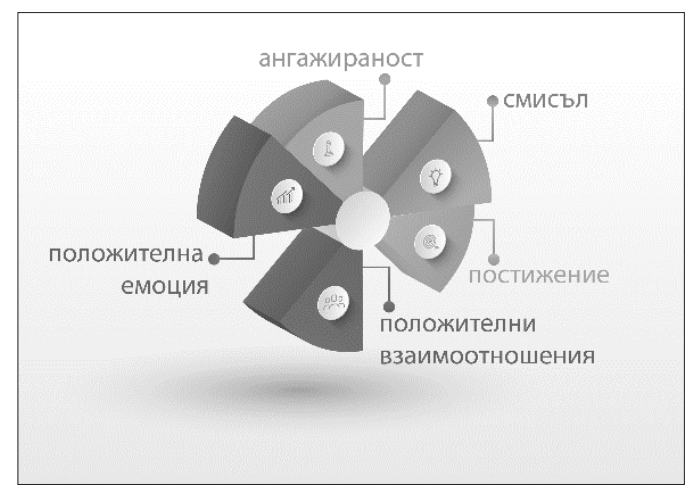

Фигура 2. Модел на теория за благополучието ПЕРМА, адаптирана по М. Seligman (2017)

M. Seligman смята, че това обучението в щастие и благополучие трябва да започне още от началното училище и да обхване по-широко родителите и техните грижи за децата, за да могат учениците да се обучават не само да разбират и ценят благоденствието, но и да се стремят към него (Seligman 2017, 117).

\section{4. Компоненти на позитивния педагогически подход}

Позитивният педагогически подход в часа на класа е ориентация към различни от традиционните в учебните часове подходи за подбор на учебно съдържание, възпитание и управление на класа, както и методи на преподаване и учене.

Той включва създаването и прилагането на по-динамичен, свободен и споделен подход за подбор и структуриране на учебно съдържание, прилагането на позитивни подходи за възпитание и управление на класа, както и последователен процес на обучение, ориентирано към компетентности (фигура 3 ).

\section{Динамичен и споделен подбор и структуриране на учебно съдържание}

Позитивният педагогически подход в часа на класа открива по-широки педагогически пространства за подбор и структуриране на учебно съдържание. Той е свързан с по-активен и по-свободен избор и структуриране на теми, задачи и дейности. Подборът и структурирането на учебно съдържание се изграждат и в процес на по-системно споделяне на отговорност с учениците и родителите. Затова класният ръководител подкрепя ученическото включване и приобщава родителите в процеса на планиране, промяна и иновации в целия процес на възпитание, управление, преподаване и учене.

Така той може да се възползва по-ефективно от предоставяните от нормативните документи педагогически възможности за динамичен, свободен и 


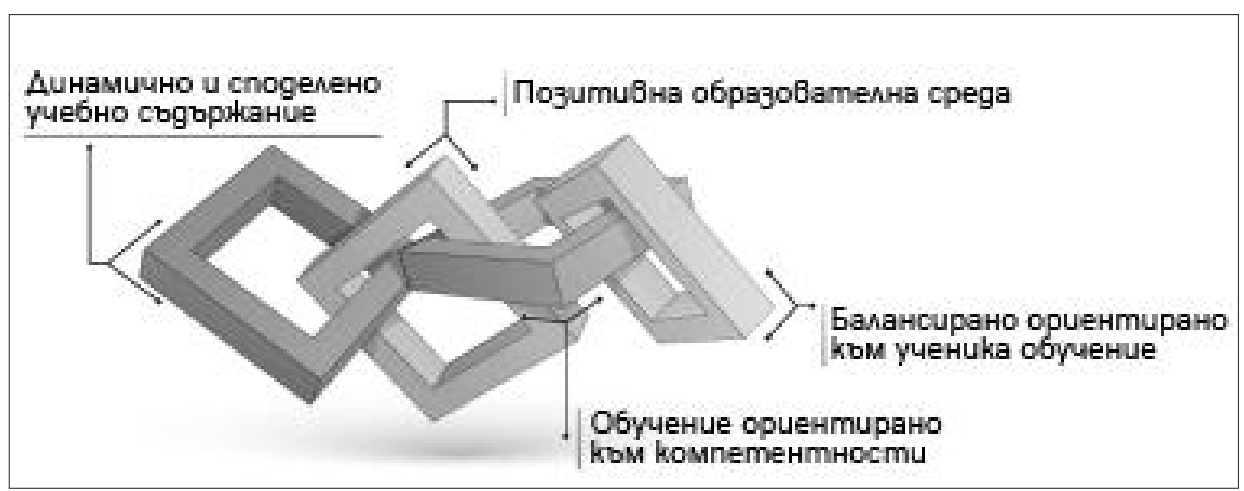

Фигура 3. Компоненти на позитивната педагогическа стратегия

споделен подбор и да ги увеличи до $30 \%$ в сравнение със задължителните и избираемите учебни часове.

\section{Позитивни подходи за възпитание и управление на класа}

Тези подходи включват създаването на позитивна образователна среда, позитивно взаимодействие в общността, развитие на позитивна Аз-концепция, автентична самооценка и Аз-ефективност. Позитивните подходи включват утвърждаване на споделено спазване на правилата и дисциплината, активно развитие на социалната и емоционалната интелигентност, както и формиране на умения и нагласа за щастие и благополучие. В нейната основа стоят стимулирането, подхранването и подкрепата на ученическото участие и самоорганизация.

В задължителните учебни часове по различните предмети в училище преобладават методите на обучение. Обикновено това е в $90 \%$ от учебното време. При позитивния педагогически подход те намаляват за сметка на методите за възпитание и управление на класа. Създават се възможности за тяхното увеличаване до $30 \%$.

\section{Компетентностно ориентиран подход на обучение}

Този подход е свързан с разширяване възможностите на обучението и насочването му от усвояване на знания към усвояване на компетентности, които освен знания включват умения и отношения, нагласи. Включването на компетентностно ориентирания подход на преподаване и учене дава нови измерения и приоритети в педагогическия процес в часа на класа. Така подходът за „овладяване на учебно съдържание“, който преобладава в традиционното обучение, се надгражда с подход, основан на преподаване и учене, ориентирани повече към умения, отношения и нагласи.

Това разширява възможностите на компетентностния подход да увеличи своето педагогическо пространство с около $10 \%$ в сравнение с подхода за усвояване на учебно съдържание при традиционното обучение. 
Ориентиран към ученика позитивен подход на възпитание, обучение..

\section{Балансиран подход на ориентирано към ученика обучение}

Позитивният педагогически подход променя съотношенията между прилаганите традиционни и индиректни методи на обучение. Така ориентирани към ученика методи и техники изместват традиционните и увеличават до $40 \%$ мястото си в часа на класа. Създават се възможности те да заемат до 60\% от учебното време при традиционно $25 \%$ използване на стратегиите, ориентирани към ученика в обучението.

Въпреки това позитивната педагогическа стратегия комбинира и балансира директните и индиректните педагогически методи и техники. Тя се развива върху концепцията, че ориентираното към ученика обучение не измества, а допълва и надгражда традиционното преподаване и учене. Въпреки че заема по-широко педагогическо пространство в часа на класа, индиректното обучение се прилага балансирано и се комбинира внимателно с директните методи на обучение.

\section{5. Основни характеристики на ориентирания към ученика педагоги- чески подход \\ Ориентация към действие}

Важна част от позитивния подход се свързва с ориентирането към активни позиции и дейности в малки групи и екипи. Те са включени в решаването на конкретни практически проблеми. В часа на класа може да се представят реални предизвикателства както от ежедневния живот на учениците, така и проблеми и предизвикателства на общността и региона.

Така учениците се включват в реална учебна практическа среда, взаимодействат си и прилагат своите академични знания в решаване на проблеми, работа по проекти, опитно-изследователска работа, решаване на екологични и здравни казуси и др.

В процеса на работа учениците споделят опит, генерират и обменят идеи и разбира се, действат активно (O'Neil 2007).

\section{Ориентация към трансфер}

Позитивният педагогически подход в часа на класа създава възможност за прилагане и пренасяне на усвоените в други учебни предмети или по неформален път знания и умения. Така учениците успешно разказват, описват, водят дискусии, пресмятат, рисуват, разработват проекти, изработват табла и постери, организират празници и др. Създават се условия за постоянен пренос на знания в нови ситуации. Учениците могат да се включат в поредица от задачи и дейности, с които да разберат, че абстрактното участие може да се отнася до конкретни дейности в клас - например като пестенето на електрическа и топлинна енергия, разделно събиране на отпадъците и др.

\section{Социална ориентация}

Важен елемент в позитивния педагогически подход в часа на класа е поширокото отваряне на ученическата общност класа към социална среда, орга- 
низирането на дебати, вертикалните интердисциплинарни и системни подходи, както и работата по проекти.

Приоритет става включването на учениците в обучение за критично и систематично мислене, съвместното вземане на решения и поемане на отговорност (Leicht, Heiss \& Byun 2018, 7).

Така традиционното преподаване и учене се надграждат с активно учене и водят до преосмисляне на педагогическите възможности на физическата и виртуалната среда както на формалното, така и на неформалното обучение като неразделна част от ученето през целия живот (Leicht, Heiss, \& Byun 2018, 8).

Подчертава се и важното значение на множество партньорства, които са установени във всеки регион, чрез които е възможно да се реализира системен и цялостен подход на общността към устойчивото развитие.

В часа на класа може да се представят реални предизвикателства както от ежедневния живот на учениците, така и проблеми и предизвикателства на общността и региона.

\section{Ситуирано учене}

Ситуираното учене свързва ефективността на обучението със социалните фактори и конкретната среда на учене. То е насочено към по-активно включване на учениците в конкретни прагматични, практически и житейски задачи вместо „сухо“ теоретично знание (Dewey 1941). Те са по-активни и съпричастни и участват в интересни и близки до интересите и живота им дейности, проучвания, задачи, проблеми и проекти.

Изучаваните художествени произведения, ситуации от новините, реалния живот, увлеченията и выпросите на учениците се използват умело за преподаване на различни теми в часа на класа. Така учениците може да пишат своите правила за „зелена класна стая““, да изготвят и реализират планове и инициативи, свързани с намаляване на риска при природни бедствия, подкрепа на инициативи на общността и др. Тези дейности създават условия за реализиране на автентични задачи от реалния живот, които увеличават ефективността на обучението (Slavin 2005, 313).

Затова позитивният педагогически подход в часа на класа се стреми да предлага повече задачи, тясно свързани с живота на малките ученици.

\section{Ориентация към интеграция и взаимодействие}

Позитивният педагогически подход в часа на класа има силно изразен интегрален характер. Той обхваща технологии както от подбора на учебно съдържание, възпитанието и управлението на класа, така и от методите на обучение на компетентности. Прилагането на различните методи в часа на класа се извършва често в интеграция и активно взаимодействие, което не е характерно за обучението по учебните дисциплини.

\section{Динамичност и иновативност}

Учебното съдържание, методите и техниките в часа на класа в различните теми варират в широки диапазони. Така може да се включват много и различ- 
ни теми и дейности, които са повлияни от различни обстоятелства - системно нарушаване на правила, деца в риск, бедствие, авария или сложна епидемиологична обстановка например.

Динамиката при методите на възпитание, управление и обучение може да включва използване предимно на ориентирани към учителя методи, например при запознаване с правила за безопасно поведение. В други случаи се използват приоритетно методи и техники, ориентирани към ученика, като работа по казус за морален избор. Често се прилага и редуване на методи и техники за управление на класа и методи на преподаване и учене.

\section{Допьлване и надграждане}

Методите на възпитание и управление на класа, както и методите на обучение в часа на класа се надграждат и допълват системно, динамично. В много случаи те се използват по-последователно при работа по една тема или в редуване на дейности. Например при усвояване на правила за безопасно пресичане се прилагат методи на разказ, демонстрация, симулативна игра, анализ на ситуация, предвиждане на последици от опасно поведение, рефлексия, групово гласуване и др.

\section{6. Методически насоки за реализация на ориентирания към ученика подход в часа на класа}

Опора на интересите на учениците. Личностно значимо знание

Интересите и увлеченията на децата често са свързани с компютърни игри, колекциониране и др. Те може успешно да се използват в различни теми в часа на класа, като заместят формулировката и мотивацията, но не и съдържанието на очакваните резултати от обучението. Така малките ученици могат да участват в полезна игра за евакуация на своите събрани кукли, животни или други при пожар, да им оказват пьрва помощ и др.

Позитивният подход стимулира и свързването на знанията с личния опит и афективност на малките ученици. Това означава темите, задачите и дейностите да бъдат по-тясно свързани с ежедневието на детето. Така учебното съдържание може да се пречупва и да включва теми, които вълнуват и ангажират малките ученици днес. Те може да са повлияни от медиите, близкото обкръжение, обществените интереси и увлечения. Включването на тези проблеми увеличава силно мотивацията на децата да учат, да усвояват процедурни знания и умения.

В часа на класа тези теми и проблеми трябва да бъдат внимателно подбрани и умело използвани. В този смисъл, дори и неприемливи концепции като например ежедневното наблюдаване на живота на хората в „реалити“ формат може да се превърне в добре организирана игра за наблюдение и коментиране на желано или нежелано, опасно или безопасно поведение или училищно правило, процедура. 


\section{Конструиране на процедурно познание}

В часа на класа много правила и процедури може да бъдат преподавани и усвоявани с по-голяма опора на познаването „как“ - например как да пресичаме на пешеходна пътека, как да работим с компютър, как да търсим информация по тема и др. Така малките ученици се насочват да усвояват знанието как да правим едни или други неща, да спазваме и прилагаме процедури в една или друга дейност, учене и общуване.

Изследванията показват, че процедурното познание е свързано с дълговременната памет. Затова умения като карането на велосипед например се забравят много по-трудно и се възстановяват след кратка ориентация по-лесно, отколкото фактите, усвоени в някой от учебните предмети. Процедурното познание е свързано с процес на автоматизиране (Sternberg \& Williams 2014, 407 - 408). Така то се оказва особено важно в усвояване на правила и процедури в класната стая, особено свързаните с безопасното поведение.

Процедурното познание има и още един аспект. Той е свързан с ориентацията на процеса на обучение не толкова към крайните резултати, колкото към процеса и начините за тяхното постигане. Така учениците овладяват умения по-лесно да търсят информация, да усвояват и градят собствен опит.

\section{Автентично учене}

Позитивният педагогически подход обхваща широки дейности, свързани с учене при което учениците се включват в дейности, близки или пряко свързани с реалния живот. То включва два важни педагогически аспекта: създаване на автентична учебна среда и включване в автентични задачи и дейности.

Създаване на автентична учебна среда

Това е среда с много близки до живота на малките ученици предмети, украса, задачи и дейности. Тя е свързана и с педагогическа дейност, която показва как знанията ще бъдат използвани в реалния живот.

Малките ученици разбират, че изучаването на правилата за безопасно поведение при наводнение ще им бъдат нужни при възникване на подобно бедствие.

Автентичната учебна среда може да бъде достатъчно ефективна и да мотивира допълнително учениците, защото я приемат като подходяща и полезна.

Много важна част от автентичната учебна среда са изработените от учениците постери, табла с успехи, интерактивни материали, дидактически гирлянди и др.

Включване в автентични задачи и дейности

Много от задачите в часа на класа може да бъдат взети или пък да бъдат насочени към реалния живот. Така някои учебни дейности се свързват с популярни сред учениците игри, филми, състезания, реалити формати, литературни герои и др.

В същото време, задачите се ориентират към участие в конкретни реални дейности. Например вместо придобиване на умения за подготовка за празник 
Ориентиран към ученика позитивен подход на възпитание, обучение...

учениците може да се включват в реална подготовка на празник в клас - украса, състезание, презентация, малко тържество, групова рисунка или друго.

Типична автентична задача е работата по подготовката на пътуване, излет, „зелен“ ден, празник на здравето, опаковките, водата и др., в които учениците осъществяват разнообразни интегрални дейности. Те може да включват проучвания, планиране, организиране и провеждане, презентации, самопредставяне и много други.

Трябва да се обърне особено внимание на възможностите на симулативните и ролевите игри, които да включат учениците до възможно най-близки автентични ситуации.

Автентичното учене трябва да се обвърже с повече изследователска и проучвателна работа, решаване на проблеми, работа по казуси, съвместни проекти и др. Учениците са стимулирани да търсят и събират повече информация, да оценяват, да търсят експертност и сътрудничество. Важно е автентичните дейности да са реални, да дават възможност за разглеждането им от различни гледни точки, да са свързани с разнообразни ресурси, да имат интегрален характер и др.

Автентичното обучение е ефективно и когато е ориентирано към дейности извън класната стая. Такива са например различни екологични инициативи, междуучилищни прояви, кореспонденция по различни теми и др.

Като много важна се определя и работата в екипи, където се „учи чрез откриване“" и съвместно изграждане на знания.

Автентичното учене трябва да завършва и с автентични оценки (Sternberg \& Williams 2014; Lombardi 2007).

В последните години концепцията за автентичното учене претърпява развитие - от подходите за „чиракуване“ през конструктивизма към конективизма и създаване на уеб базирана автентична учебна среда.

\section{Преподаване и учене, основано на постижения}

Позитивният педагогически подход в часа на класа стимулира стремежа на малките ученици към успех и самоутвърждаване. Той се реализира в два подхода.

На първо място, това е подборът на задачите, проучванията, екипните дейности и др. Те трябва да бъдат внимателно прецизирани, за да може да бъдат изпълнени реално от малките ученици. В някои случаи това е свьрзано и с опростяване на задачите и диференциран подход. Даването на домашни работи в часа на класа в много случаи може да бъде неефективен педагогически подход. Той е добре да се замества от проучвания, малки презентации, проекти и др.

Вторият подход се основава на системна подкрепа на постиженията на учениците във всички теми и дейности. Тя се осъществява както по време на провеждане на часа, така и при обобщения, празници, тьржества и др. Подкрепата е разнообразна и включва стимули като табла на успехите и възлагане на нови задачи и роли. 


\section{Преподаване и учене, основано на положителните взаимоотношения}

Това е важна част от позитивния педагогически подход, насочен към укрепване на добрите взаимоотношения, разбирателството и сьтрудничеството в тях. Добрите взаимоотношения са свързани и с усвояване на правила за делово общуване и култура на поведение. Голяма част от нея е свързана с усвояване на умения за комуникация и позитивно общуване, работа в екип и учене.

\section{7. Заключение}

Позитивният педагогически подход в часа на класа е успешно приложен и апробиран в началния етап на обучение. В непосредствената практическа работа участват повече от 2400 ученици, които работят по структурирани теми, задачи и дейности в ежеседмични часове на класа през цялата учебна година. Проследено е развитието на подхода при два випуска. Така учениците работят в цялостен завършен период от четири години.

Резултатите от апробацията показват, че този подход е предпочитан от много класни ръководители поради своята систематичност и балансираност и прагматичност.

Много добре се развива и надграждането на активното учене и създаването на позитивна образователна среда, която се свързваше и с увеличаване на ученическото участие и включване.

Успешното апробиране на позитивния педагогически подход в часа на класа се потвърждава по няколко основни критерия: академични постижения, мотивация и ученическо участие, личностно развитие, отношение към общността, активност и инициативност, критично мислене и умения за планиране и предвиждане, спазване на правила и желано поведение, както и позитивна самооценка и рефлексивност.

Всичко това дава основание да се смята, че описаният педагогически подход е ефективна позитивна педагогическа стратегия в часа на класа.

\section{БЕЛЕЖКИ}

1. Закон, 2017.

2. https://dictionary.cambridge.org

\section{ЛИТЕРАТУРА}

BLUMBERG, P., 2009. Developing Learner-centered teaching: A practical guide for faculty. San Francisco: Jossey-Bass.

BRUNER, J. S., 1961. The act of discovery. Harvard Educational Review, 31, $21-32$.

DeCarvalho, R., 1991. The humanistic paradigm in education. The Humanistic Psychologist, 19(1), 88 - 104. 
ВИГОТСКИ, Л., 1983. Мислене и реч. София: Наука и изкуство.

ДЮИ, Дж., 1941. Опитьт като основа на образованието. София: Стоян Георгиев.

JOHNSON, D. \& JOHNSON, F., 2013. Joining together: group theory and group skills. London: Pearson.

LEICHT, A. HEISS, J. \& BYUN, W., 2018. Issues and Trends in Education for Sustainable Development. Paris: UNESCO.

LOMBARDI, M.M., 2007. Authentic learning for the 21st century: An overview ELI Report No.1. Boulder, CO: EDUCAUSE Learning Initiative.

МАСЛОУ, А., 2010. Мотивачия и личност. София: Кибеа.

ПАНИНА, Т., ВАВИЛОВА, Л., 2007. Современные способы активизации обучения. Москва: Академия.

РАДЕВ, Пл., 2010. Конструктивистка дидактика. Пловдив: Паисий Хилендарски.

РОДЖЪРС, К., 2015. Начин да бъдеш. София: Изток-Запад.

СЕЛИГМАН, М., 2017. Благоденствие. София: Хермес.

СЛАВИН, Р., 2005. Педагогическа психология. София: Наука и изкуство.

СТЪРНБЪРГ, Р., Уилямс, У., 2014. Педагогическа психология. София: Изток-Запад.

O’NEILL, G. \& MCMAHON, T., 2005. Student centered learning: what does it mean for students and lecturers? Dublin: University College Dublin.

PATTERSON, C., 1973. Humanistic education. Englewood Cliffs. NJ: Prentice-Hall.

PATTERSON, C., 1987. What has happened to humanistic education? Michigan Journal of Counseling and Development, 18, 9-10.

\section{REFERENCES}

BLUMBERG, P., 2009. Developing Learner-centered teaching: A practical guide for faculty. San Francisco: Jossey-Bass. 31, 21-32.

DECARVALHO, R., 1991. The humanistic paradigm in education. The Humanistic Psychologist, 19(1), 88 - 104.

JOHNSON, D. \& JOHNSON, F., 2013. Joining together: group theory and group skills. London: Pearson.

LEICHT, A. HEISS, J. \& BYUN, W., 2018. Issues and Trends in Education for Sustainable Development. Paris: UNESCO.

LOMBARDI, M.M., 2007. Authentic learning for the 21st century: An overview ELI Report No. 1. Boulder, CO: EDUCAUSE Learning Initiative.

O'NEILL, G. \& MCMAHON, T., 2005. Student centered learning: what does it mean for students and lecturers? Dublin: University College Dublin. 
PATTERSON, C., 1973. Humanistic education. Englewood Cliffs. NJ: Prentice-Hall.

PATTERSON, C., 1987. What has happened to humanistic education? Michigan Journal of Counseling and Development, 18, $9-10$.

RADEV, P1., 2006. Konsruktivistka didaktika. Plovdiv: Paisii Hilendarski [In Bulgarian].

RODGERS, K., 2015. A way of beginning. Sofia: East-West.

SELIGMAN, M. (2017). Flourish. Sofia: Hermes.

SLAVIN, R., 2005. Educational Psychology. Sofia: Nauka i izkustvo.

STERNBERG, R., WILLIAMS, W., 2014. Educational Psychology. Sofia: Iztok-Zapad.

VYGOTSKY, L., 1983. Thought and language. Sofia: Nauka i izkustvo.

\title{
STUDENT-CENTERED POSITIVE APPROACH TO EDUCATION, TRAINING AND SOCIALIZATION IN THE CLASS TIME LESSONS
}

\begin{abstract}
The article examines the student-centered positive pedagogical approach in the class time lessons. It reviews the term's definition and its connection to humane pedagogy, positive psychology and pedagogy. A constructed model for teaching and learning is described and four main components are viewed: dynamic and shared model for selection and structuring of the learning content; positive approach to education and classroom management; competence-oriented training; balanced approach to student-centered learning. Methodological guidelines for the realization of the student-centered positive pedagogical approach in the classroom are also indicated.

Keywords: student-teacher class; class time lessons; positive pedagogical approach; approaches and teaching methods in the class time lessons

$\triangle$ Dr. Lyuben Vitanov, Assoc. Prof. ORCID ID: 0000-0002-1294-7133 Faculty of Educational Studies and Arts

Sofia University

Sofia, Bulgaria E-mail: lvitanov@uni-sofia.bg
\end{abstract}

